Fixed Point Theory, 23(2022), No. 1, 105-126

DOI: $10.24193 /$ fpt-ro.2022.1.07

http://www.math.ubbcluj.ro/ nodeacj/sfptcj.html

\title{
KRASNOSELSKII TYPE THEOREMS IN PRODUCT BANACH SPACES AND APPLICATIONS TO SYSTEMS OF NONLINEAR TRANSPORT EQUATIONS AND MIXED FRACTIONAL DIFFERENTIAL EQUATIONS
}

\author{
SANA HADJ AMOR*, RADU PRECUP** AND ABDELHAK TRAIKI* \\ * Department of Mathematics, LR 11 ES 35, \\ Higher School of Science and Technology, \\ University of Sousse, Tunisia \\ E-mail: sana.hadjamor@yahoo.fr, abdelhak.traikii@gmail.com \\ **Faculty of Mathematics and Computer Science \\ and \\ Institute of Advanced Studies in Science and Technology, \\ Babes-Bolyai University, 400084 Cluj-Napoca, Romania \\ and \\ Tiberiu Popoviciu Institute of Numerical Analysis, \\ Romanian Academy, P.O. Box 68-1, 400110 Cluj-Napoca, Romania \\ E-mail: r.precup@math.ubbcluj.ro
}

\begin{abstract}
In this paper, we use a new technique for the treatment of systems based on the advantage of vector-valued norms and of the weak topology. We first present vector versions of the Leray-Schauder alternative and then some Krasnoselskii type fixed point theorems for a sum of two mappings. Applications are given to a system of nonlinear transport equations, and systems of mixed fractional differential equations.

Key Words and Phrases: Krasnoselskii fixed point theorem for a sum of operators, weak topology, generalized contraction, product Banach space, vector-valued norm, system of nonlinear transport equations, convergent to zero matrix, fractional integral.

2020 Mathematics Subject Classification: 47B38, 47H09, 47H08, 47H10.
\end{abstract}

\section{REFERENCES}

[1] J. Appell, E. De Pascale, Su alcuni parametri connessi con la misura di non compattezza di Hausdorff in spazi di funzioni misurabili, Boll. Un. Mat. Ital., B(6)(1984), no. 3, 497-515.

[2] O. Arino, S. Gautier, J.P. Penot, A fixed point theorem for sequentially continuous mappings with applications to ordinary differential equations, Funkc. Ekvacial, 27(1984), 273-279.

[3] C.S. Barroso, E.V. Teixeira, A topological and geometric approach to fixed point results for sum of operators and applications, Nonlinear Anal., 60(2005), no. 4, 625-660.

[4] A. Ben Amar, I. Feki, A. Jerbi, Leray-Shauder and Furi-Pera types fixed point theorems for the sum of two weakly sequentially continuous mappings and application to transport equation, Afrika Mat., 25(2014), 707-722. 
[5] A. Ben Amar, A. Jeribi, M. Mnif, On a generalization of the Schauder and Krasnoselskii fixed point theorems on Dunford-Pettis spaces and applications, Math. Methods. Appl. Sci., 28(2005), 1737-1756.

[6] A. Ben Amar, M. Mnif, Leray-Schauder alternatives for weakly sequentially continuous mappings and application to transport equation, Math. Methods Appl. Sci., 33(2010), 80-90.

[7] T. Cardinali, R. Precup, P. Rubbioni, Two abstract approaches in vectorial fixed point theory, Quaest. Math., 41(2018), 173-188.

[8] F.S. De Blasi, On a property of the unit sphere in Banach spaces, Bull. Math. Soc. Sci. Math. Roumanie, 21(1977), 259-262.

[9] N. Dunford, J.T. Schwartz, Linear Operators, Part I: General Theory, Interscience Publishers, New York, 1958.

[10] R.E. Edwards, Functional Analysis, Theory and Applications, Holt, Reinhart and Winston, New York-Toronto-London, 1965.

[11] A. Guezane-Lakoud, S. Ramdane, Existence of solutions for a system of mixed fractional differential equations. Journal of Taibah University for Science, 12(2018), no. 4, 421-426.

[12] I.M. James, Topological Vector Spaces, Springer, New York, 1987.

[13] M.A. Krasnosel'skii, Two remarks on the method of successive approximations, (Russian), Uspehi Mat. Nauk, 10(1955), 123-127.

[14] K. Latrach, M.A. Taoudi, Existence results for a generalized nonlinear Hammerstein equation on $L_{1}$ spaces, Nonlinear Anal., 66(2007), 2325-2333.

[15] K. Latrach, M.A. Taoudi, A. Zeghal, Some fixed point theorems of the Schauder and the Krasnosel'skii type and application to nonlinear transport equations, J. Diff. Equ., 221(2006), 256271.

[16] A.I. Perov, On the Cauchy problem for a system of ordinary differential equations, (Russian), Priblizhen. Metody Reshen. Differ. Uravn., 2(1964), 115-134.

[17] I.-R. Petre, A. Petrusel, Krasnoselskii's theorem in generalized Banach spaces and applications, Electron. J. Qual. Theory Differ. Equ., 85(2012), 20 pp.

[18] B.J. Pettis, On integration in vector spaces, Trans. Am. Math. Soc., 44(1938), 277-304.

[19] R. Precup, Methods in Nonlinear Integral Equations, Kluwer, Dordrecht, 2002.

[20] R. Precup, The role of matrices that are convergent to zero in the study of semilinear operator systems, Mathematical and Computer Modelling, 49(2009), no. 3-4, 703-708.

[21] H.H. Schaefer, Neue existenzsä tze in der theorie nichtlinearer integragleichungen, Sitzungsdh. Sächs. Akademie Wiss. Leipzig Matematisch-Naturwissenchaftliche, 1955, 101:7-40.

[22] A. Viorel, Contributions to the study of nonlinear evolution equations, Ph.D. Thesis, BabeşBolyai University, Cluj-Napoca, 2011.

Received: June 23, 2020; Accepted: September 19, 2020. 
